NoTe

\title{
Prevalence of Maturity-onset Isolated ACTH Deficiency (IAD) in 2005: Japanese Cohort Studies
}

\author{
TOSHIHIDE YAMAMOTO AND KYUZI KAMOI* \\ Yamamoto Naika Clinic, 3rd Fl. Thickland Bldg. 2 3-5 Namba, Osaka, 542-0076, Japan \\ *Department of Medicine, Nagaoka Red Cross Hospital, 2-297-1 Sensyu, Nagaoka, Niigata, 940-2085, Japan
}

\begin{abstract}
The prevalence of isolated ACTH deficiency (IAD) in Japan remains to be determined. Both authors (T.Y. \& K.K.) had unique opportunities to see all patients with maturity-onset IAD in particular areas. T.Y. regularly visited Tokunoshima Island in Kagoshima Prefecture (population of about 28,500) which has two acute-care hospitals. He has taken care of endocrine-metabolism cases in one hospital and kept in touch with an endocrine-oriented physician in another. K.K. has provided glucocorticoid supplementation for all patients with maturity-onset IAD as the patients' own physician in a hospital which provided medical care for the Chuetsu district in Niigata Prefecture with 527,407 inhabitants in 2005. Four male patients (average age at onset, 70.0 years; range, 67-75 years) were identified in Tokunoshima over the 10-year period and 20 patients (15 males and 5 females; average age at onset, 63.9 years; range, 49-77 years) were cared for in the Chuetsu district in 2005. The estimated prevalence of IAD from the numbers of IAD patients and of inhabitants in the periods cited from the national population survey was 7.3 per 100,000 (an average in 10-year period) in Tokunoshima and 3.8 per 100,000 in the Chuetsu district in 2005. Maturity-onset IAD in Japan thus is not very rare in the elderly.
\end{abstract}

Key words: Maturity-onset isolated ACTH deficiency, Prevalence, Japan

(Endocrine Journal 55: 939-941, 2008)

OVER 300 cases of isolated ACTH deficiency (IAD) have been reported between 1969 and 1994 in Japan [1]. Katakami and coworkers estimated the prevalence of IAD in 2005 in Miyazaki Prefecture as 1.91 per 100,000 persons based on patients diagnosed in Miyazaki University Hospitals, nine other hospitals and in several medical school-affiliated hospitals and clinics, because 22 patients (range at onset, 11-96 years; 4 juvenile onset IAD and 18 maturity-onset IAD) on 2005 were identified in Miyazaki Prefecture with 1150,000 inhabitants [2].

The numbers of patients with IAD and the numbers of inhabitants in a particular area at a certain time have to be known in order to assess the prevalence of IAD,

Received: May 15, 2008

Accepted: May 27, 2008

Correspondence to: Toshihide YAMAMOTO, Yamamoto Naika Clinic, 3rd Fl. Thickland Bldg. 2-3-5 Namba, Osaka, 542-0076, Japan data of which the hospital-based endocrinologist has no opportunity to obtain. Both authors had a special interest in IAD and unique opportunities to see all patients with IAD in two particular areas during certain periods of time.

For more than 10 years, one of the authors (T.Y.) regularly visited Tokunoshima Island in Kagoshima Prefecture, which is located in the southern part of Japan. There were two acute-care hospitals with inpatient facility on the island. He has taken care of endocrine-metabolism cases, as well as unclassified difficult medical cases, in one hospital and kept in touch with an endocrine- oriented physician in another hospital. He was consulted when patients were admitted to either hospital for prostration with hyponatremia or hypoglycemia without apparent reason, and he diagnosed 4 patients as having maturity-onset IAD. As the size of the population on the island was admittedly small to estimate the prevalence of IAD, the prevalence in 2005 was sought as an average value over a 
Table 1. Prevalence of isolated ACTH deficiency in the Tokunoshima Island

\begin{tabular}{|c|c|c|c|c|c|c|c|}
\hline \multirow{2}{*}{ year } & \multirow{2}{*}{ inhabitants } & \multicolumn{4}{|c|}{ patients } & \multirow{2}{*}{ sum } & \multirow{2}{*}{$\begin{array}{l}\text { per } 100,000 \\
\text { inhabitants }\end{array}$} \\
\hline & & A & B & $\mathrm{C}$ & $\mathrm{D}$ & & \\
\hline 1996 & 29,218 & 0 & & & & 1 & 3.4 \\
\hline 1997 & 29,409 & $\bigcirc$ & 0 & & & 2 & 6.8 \\
\hline 1998 & 29,015 & $\bigcirc$ & $\bigcirc$ & & & 2 & 6.9 \\
\hline 1999 & 28,880 & $\bigcirc$ & $\bigcirc$ & & & 2 & 6.9 \\
\hline 2000 & 28,628 & $\bigcirc$ & $\bigcirc$ & & & 2 & 7.0 \\
\hline 2001 & 28,560 & 0 & $\bigcirc$ & & & 2 & 7.0 \\
\hline 2002 & 28,424 & $\bigcirc$ & $\bigcirc$ & & & 2 & 7.0 \\
\hline 2003 & 28,329 & $\bigcirc$ & $\bigcirc$ & $\bigcirc$ & & 3 & 10.6 \\
\hline 2004 & 28,184 & $\bigcirc$ & & 0 & & 2 & 7.1 \\
\hline 2005 & 28,090 & $\bigcirc$ & & $\bigcirc$ & 0 & 3 & 10.7 \\
\hline Average & 28,674 & & & & & 2.1 & 7.3 \\
\hline
\end{tabular}

10-year period from 1996 till 2005.

Another author (K.K.) provided maintenance of glucocorticoid supplementation for all patients with maturity-onset IAD at the Nagaoka Red Cross Hospital as kakaritsuke-i (the patients' own physician) following the 2004 Mid-Niigata Prefecture (Chuetsu district) earthquake, which was located near the central part of Japan [3]. This hospital has managed all patients with IAD in the Chuetsu district, which has a relatively large population of 527,407 inhabitants in 2005, since there was no expert in dealing patients with IAD in other area hospitals. In addition, the demographic changes in this area have remained small for the past 20 years, which is useful for calculating the prevalence of IAD.

The effects of CRH injection on ACTH release, the secretory reserve of the other anterior pituitary hormones by the respective stimulatory maneuvers and the adrenal response to exogenous ACTH have been described elsewhere $[2,5]$.

Four male patients (designated as patients A, B, C, $\mathrm{D}$, average age at onset, 70.0 years; range, 67-75 years) were identified on Tokunoshima over a 10-year period (Table 1), and in the Chuetsu district, the first patient was recorded in 1985 and afterward, 20 (15 males and 5 females; average age at onset, 63.9 years; range, 49-77 years) of 22 patients with IAD ( 2 had died) in 2005 were cared for in the Nagaoka Red Cross Hospital.
The prevalence of IAD was estimated based on the numbers of IAD patients and the numbers of inhabitants in the periods cited from the national population surveys [4]. The prevalence of IAD on Tokunoshima in 2005 was 7.3 per 100,000 inhabitants calculated as an average value in the preceding 10 years (Table 1), while the prevalence in the Chuetsu district in 2005 was 3.8 per 100,000 inhabitants since the total number of inhabitants in the area was 527,407 in 2005. IAD is generally latent in the elderly unless it is being aggravated by acute illness [5]. As both hospitals in Tokunoshima are oriented to acute care, the medical staffs appear to have more chance to encounter patients with IAD. Furthermore, the prevalence of IAD on Tokunoshima in 1996, which had all patients with maturity-onset IAD, was similar to that in the Chuetsu district in 2005 and increased 3 times in 2005 (Table 1). As a person in Tokunoshima has a longer life than in the Chuetsu district, these may be the reasons for the difference of prevalence between the two areas.

Although these prevalences of IAD are lower than those of Addison's disease reported, i.e. 11.0 [6], 9.2 [7] and 14.0 [8] per 100,000 persons in Europe, they are 2.0 to 3.8 times higher than the prevalence of juvenile and maturity-onset IADs estimated previously by Katakami et al. [2]. IAD is not a very rare disease in the Japanese elderly and more aggressive case-finding among the elderly is desirable. 


\section{References}

1. Hashimoto K (1995) Isolated ACTH deficiency. Endocrinol Diabetol 1: 103-111 (in Japanese).

2. Katakami H, Ishikawa E, Hidaka H, Atoda Y, Yamaguchi H, Yonekawa T, Kuribayashi T, Matsukura $\mathrm{S}$ (2007) (Clinical feature, incidence, and prevalence of isolated ACTH deficiency (IAD)). ACTH related Peptides 18: 29-32 (in Japanese).

3. Kamoi K, Tanaka M, Ikarashi T, Miyakoshi M (2006) Effect of the $2004 \mathrm{mid}$ Niigata prefecture earthquake on patients with endocrine disorders. Endocr $J$ 53: 511-521.

4. Population Survey of Residents, 8th year through 17th year of Heisei, Bureau of Statistics, Ministry of Internal Affairs and Communications (Jyuumin Kihon
Daichou Jinkou Youran Heisei 8 nen till Heisei 17 nen, Soumu-sho, Toikeikyoku) (in Japanese).

5. Yamamoto T (2008) Isolated ACTH deficiency (IAD): Latent Nature in Adults. The Endocrinologist (in press).

6. Kong MF, Jeffcoate W (1995) Eighty-six cases of Addison's disease. Clin Endocrinol (Oxf) 43: 130-131.

7. Willis AC, Vince FP (1997) The prevalence of Addison's disease in Coventry, UK. Postgrad Med J 73: 286-288.

8. Lovas K, Husebye ES (2002) High prevalence and increasing incidence of Addison's disease in western Norway. Clin Endocrinol (Oxf) 56: 787-791. 